\title{
Utility of the Ceftazidime-Imipenem Antagonism Test (CIAT) to Detect and Confirm the Presence of Inducible AmpC Beta-Lactamases Among Enterobacteriaceae
}

\author{
Vlademir Vicente Cantarelli1,2,3, Everton Inamine ${ }^{2}$, Teresa Cristina Z. Brodt ${ }^{2}$, \\ Carina Secchi ${ }^{2}$, Bianca C. Cavalcante ${ }^{2}$ and Fabiana de Souza Pereira ${ }^{1}$ \\ ${ }^{1}$ Molecular Biology \& ${ }^{2}$ Microbiology sections, Weinmann Laboratório LTDA, Porto Alegre, RS; \\ ${ }^{3}$ Feevale Universitary Centre, Novo Hamburgo, RS, Brazil
}

\begin{abstract}
Detection of AmpC beta-lactamase production by enterobacteria has been problematic. Contrary to ESBLs, no specific guidelines are available for detection and confirmation of AmpC production by clinical relevant microorganisms. Moreover, some bacterial species may produce inducible AmpC beta-lactamases that can be easily overlooked by routine susceptibility tests. We reported here a new test based on the strong inducible effect of imipenem on AmpC genes and the consequent antagonism with ceftazidime. This test is very simple and proved to be helpful in detecting AmpC-inducible enzymes among several species of clinical isolates.

Key-Words: AmpC, inductible beta-lactamases, screening tests, imipenem, cefoxitin screening.
\end{abstract}

Production of enzymes that hydrolyze beta-lactam antibiotics is one of the major mechanisms of bacterial resistance [1,2]. Several members of Enterobacteriaceae are naturally resistant to ampicillin and first generation cephalosporins due to the production of chromosomally encoded beta-lactamases, collectively called class $\mathrm{C}$ or AmpC beta-lactamases [3]. Furthermore, point mutation in these ampC genes may confer resistance to virtually all cephalosporins and monobactams, with the possible exception of cefepime, cefpirome and the carbapenems [4]. Cefepime resistance, however, has already been reported among AmpC-producing strains [5,6]. Moreover, plasmids containing derivatives of the chromosomally encoded AmpC cephalosporinases are becoming disseminated among enterobacteria, thus providing a new mechanism of resistance for those originally AmpCdeficient bacterial strains [4,7]. Chromosomal AmpC betalactamases are usually inducible, while, except for DHA enzymes, plasmid-mediated AmpC enzymes are not [4,8,9].

Clinical microbiology laboratories should be able to detect bacterial strains producing AmpC enzymes, since these strains may appear susceptible to a particular beta-lactam antibiotic in vitro, but show no clinical response when used to treat serious infections [10]. The former National Committee for Clinical Laboratory Standards (NCCLS, now CLSI) guidelines for performing in vitro susceptibility tests have included procedures for screening and confirmation of ESBL-producing microorganisms [11]; however, it does not contain any information on AmpC detection or confirmation. Recently proposed tests for AmpC beta-lactamases include: use of new beta-lactamase inhibitors [12], phenotypic tests [8], PCR for plasmid-mediated $a m p C$ genes [13], and even DNA chips [14]. These tests either depend on drugs not widely available or

Received on 1 October 2006; revised 24 March 2007.

Address for correspondence: Dr. Vlademir Vicente Cantarelli. Weinmann Laboratório LTDA. Ramiro Barcelos 910, Porto Alegre, RS. Zip code: 90035-001, Brazil. Phone: 55 - 51 - 3314 - 3850. Fax: 55 - 51 3311 - 7813. E-mail: vcantarelli@weinmann.com.br.

The Brazilian Journal of Infectious Diseases 2007;11(2):237-239. (C) 2007 by The Brazilian Journal of Infectious Diseases and Contexto Publishing. All rights reserved. are still too cumbersome or technically demanding to be widely used by clinical microbiology laboratories.

We reported here the utility of a phenotypic test to detect and confirm the presence of inducible AmpC beta-lactamases among enterobacterial strains, based on the strong inducing effect of imipenem on these enzymes [15,16].

\section{Materials and Methods}

Bacterial strains isolated from clinical samples such as urine, blood, sputum, and swabs from hospitalized patients were represented by several members of Enterobacteriaceae, showing resistance to a $30 \mu \mathrm{g}$-cefuroxime disk [15]. Identification at species level was performed using the Vitek system (bioMérieux, France) or 16S rDNA sequencing [17]. Susceptibility tests were done by a standard disk diffusion method (Oxoid, Hampshire, UK), and screening for extended spectrum beta-lactamase (ESBL) was performed following the NCCLS guidelines [11], and then confirmed using both ceftazidime plus cefotaxime disks, both with and without clavulanate [11] and the double-disk approximation test [18]. Thirty-four cefuroxime-resistant strains were negative for ESBL and they all showed evidence of AmpC beta-lactamase production, as judged by the ceftazidime-imipenem antagonism test (CIAT), which consisted of a imipenem disk $(10 \mu \mathrm{g})$ placed $20 \mathrm{mM}$ apart (edge-to-edge) from a ceftazidime disk (30 $\mu \mathrm{g})$ on a Mueller-Hinton agar plate previously inoculated with a $0.5 \mathrm{McF}$ arland bacterial suspension, and incubated for $24 \mathrm{~h}$ at $35^{\circ} \mathrm{C}$. For comparison, a cefoxitin disk was also placed $20 \mathrm{mM}$ apart from the ceftazidime disk (Figure 1A). Antagonism, indicated by a visible reduction in the inhibition zone around the ceftazidime disk adjacent to the imipenem or cefoxitin disks, was regarded as positive for inducible AmpC beta-lactamase production, and further confirmed using molecular testing. Whenever necessary, the presence of ESBL (e.g. bla $a_{\mathrm{TEM}}$ and $b l a_{\mathrm{SHV}}$ ) or AmpC were confirmed by PCR amplification followed by DNA sequencing using the BigDye Terminator kit (Applied Biosystems) $[9,13,19,20,21]$. Multiple PCR runs and sequencing were performed for each enzyme to insure that a Taq polymerase error had not occurred. 


\section{Results}

A total of 34 cefuroxime-resistant and ESBL-negative enterobacterial strains were CIAT positive, indicating the production of inducible AmpC beta-lactamases. Among them, $1 \mathrm{~K}$. pneumoniae strain and 1 Proteus mirabilis strain were CIAT positive, and the respective enzymes were identified as bla $a_{\mathrm{DHA}}$ by PCR with specific primers [9]. Further characterization of these genes by nucleotide sequencing analysis showed $100 \%$ homology with bla $a_{\mathrm{DHA}-1}$ for $K$. pneumoniae. The P. mirabilis sequence revealed only $95 \%$ nucleotide homology with $b l a_{\mathrm{DHA}}$ ${ }_{1}$, resulting in $97.3 \%$ identity with bla $a_{\text {DHA-1 }}$ and bla $a_{\text {DHA-2 }}$ (Fig. $1 B$ ) and was provisionally called DHA-3. All the other 32 CIAT positive strains consisted of species known to naturally produce inducible AmpC beta-lactamases. Twenty-one of these strains belonged to the genus Enterobacter. Homology search (DDJB) showed that 2 Enterobacter strains harbored ampC genes that were 99.3 and $100 \%$ homologous to ACT-1, respectively, suggesting that they may be in fact $E$. asburiae species [22]. All other ampC genes could be arranged into 2 subclasses, as previously described for Enterobacter spp. [23]: (i) 7 strains containing ampC genes close to ( $\geq 99.8 \%$ homology) bla $_{\mathrm{MNH}-1}$ from E. cloacae (GenBank accession number X08082), and (ii) 12 strains with ampC genes highly homologous ( $\geq 99.6 \%)$ to the chromosomal ampC gene of E. cloacae Q908R (X08081).

$M$. morganii was the second most common pathogen harboring inducible AmpC beta-lactamase. DNA sequencing revealed $100 \%$ homology with bla ${ }_{\mathrm{DHA}-1}$ for 8 of these strains, in accordance with previous reports [24,25]. One $M$. morganii strain harbored an ampC gene that was $100 \%$ homologous to the sequence of a $M$. morganii ampC gene described as MOR-2 in the DDJB databank (accession number AY235804). The ampC gene from 1 Citrobacter freundii strain was similar to bla $_{\mathrm{CMY}-13}(97.6 \%$ identity).

\section{Discussion}

In this study, we used imipenem, a potent inducer of $a m p C$ genes, together with ceftazidime to detect inducible AmpC betalactamases $[9,15,16]$. Obviously, the CIAT test can not be used to

Figure 1. Detection of Amp-C beta-lactamases using CIAT. (A) Bacterial strains and the respective enzymes are indicated. E. coli ATCC 25922 is a negative control and the K. pneumoniae strain shows that the test is negative (i.e. not affected) for ESBL. For some strains, the blunting of ceftazidime zone (center) by imipenem-induced enzyme (right side) is more pronounced, compared with the cefoxitin-induced enzyme (left side). Note the intermediate resistance for cefoxitin (disk on the left) for DHAproducing organisms. (B) Comparison of the deduced amino acid sequences of AmpC beta-lactamase of $P$. mirabilis with DHA1, DHA-2, and MOR-2 from M. morganii. Distinct amino acids found in this P. mirabilis beta-lactamase (here designated DHA3) are shown in bold.

\section{A}
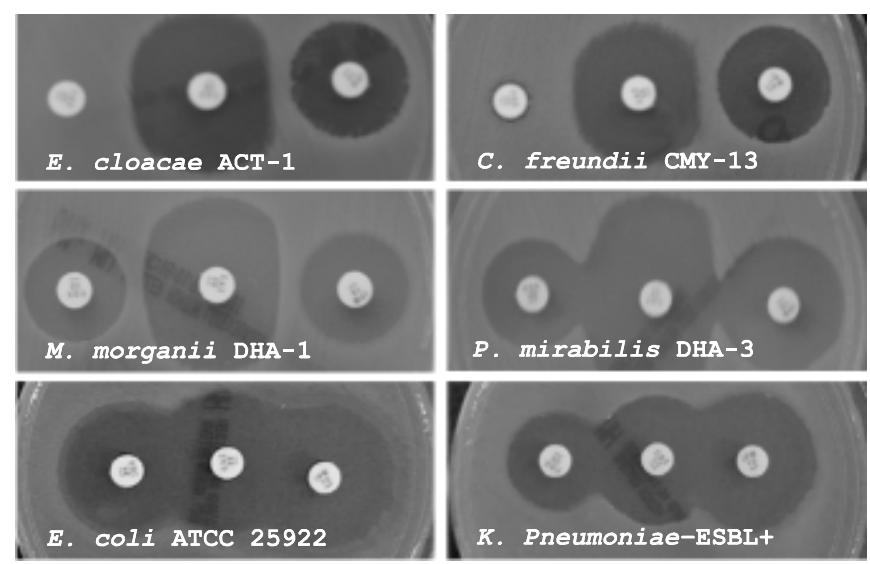

\section{B}

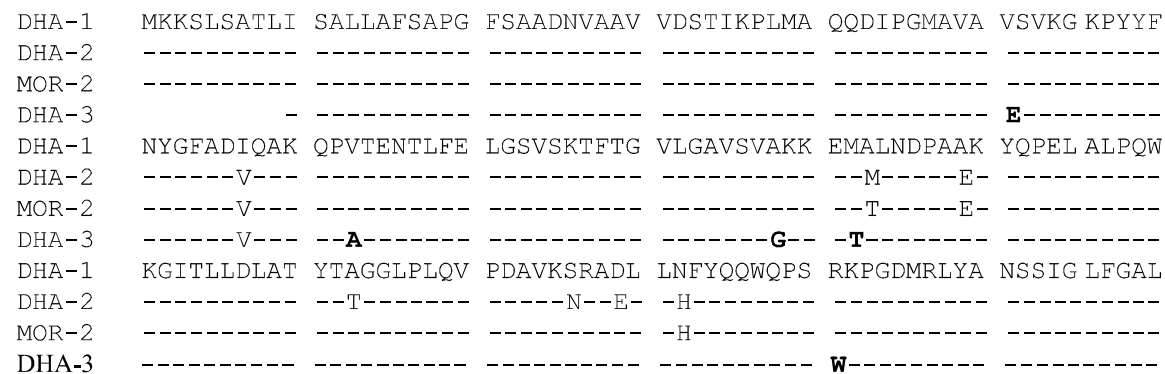

www.bjid.com.br 
test strains showing no inhibition zone for ceftazidime or for those strains bearing plasmid-mediated AmpC enzymes that are not typically inducible. However, such strains are readily identified by their resistance profile, e.g. being susceptible only to cefepime and carbapenems [26]. On the other hand, detection of inducible AmpC enzymes is much more challenging. Susceptibility tests often do not detect resistance to third generation cephalosporins, and the clinical use of these cephalosporins could segregate resistant mutants that would ultimately result in therapeutic failure [26-28]. Resistance to cefoxitin alone ( $\leq 18 \mathrm{mM}$ inhibition zone) was reported to overestimate the presence of AmpC betalactamases among Enterobacteriaceae $[8,18]$. To aggravate the problem, it is also known that $E$. coli harboring bla ${ }_{\mathrm{ACC}-1}$ can be susceptible to cefoxitin, while strains with bla $a_{\mathrm{DHA}-2}$ can have intermediate resistance for this drug [4]. This was the case of all strains harboring bla ${ }_{\mathrm{DHA}}$ genes in this study, with the exception of one cefoxitin-resistant $K$. pneumoniae bearing $b l a_{\mathrm{DHA}-1}$. A combination of mechanisms, such as loss of membrane permeability or hyper-production of the AmpC enzyme could explain this finding. On the other hand, decreased susceptibility to cefoxitin is also found among nonAmpC producers, which makes screening with cefoxitin unreliable to detect AmpC production $[8,18]$.

The CIAT is a simple test that can be used to confirm the presence of known, as well as new, inducible ampC enzymes, among enterobacterial strains. The test can be done directly on the initial susceptibility test or in combination with other disks used to detect ESBL production.

\section{References:}

1. Bradford P.A. Extended-spectrum beta-lactamases in the 21st century: characterization, epidemiology, and detection of this important resistance threat. Clin Microbiol Rev 2001;14:933-51.

2. Nordmann P. Trends in beta-lactam resistance among Enterobacteriaceae. Clin Infect Dis 1998;27:(Suppl 1)100-6.

3. Bush K., Jacoby G.A., Medeiros A.A. A functional classification scheme for $\beta$-lactamases and its correlation with molecular structure. Antimicrob Agents Chemother 1995;39:1211-33.

4. Philippon A., Arlet G., Jacoby G.A. Plasmid-determined AmpC-type beta-lactamases. Antimicrob Agents Chemother 2002;46:1-11.

5. Barnaud G., Benzerara Y., Gravisse J., et al. Selection during cefepime treatment of a new cephalosporinase variant with extended-spectrum resistance to cefepime in an Enterobacter aerogenes clinical isolate. Antimicrob Agents Chemother 2004;48:1040-2.

6. Mammeri H., Poirel L., Bemer P., et. al. Resistance to cefepime and cefpirome due to a 4-amino-acid deletion in the chromosome-encoded AmpC $\beta$-lactamase of a Serratia marcescens clinical isolate. Antimicrob Agents Chemother 2004;48:716-20.

7. Walther-Rasmussen J., Hoiby N. Plasmid-borne AmpC betalactamases. Can J Microbiol 2002;48:479-93.

8. Coudron P.E., Moland E.S., Thomson K.S. Occurrence and detection of AmpC beta-lactamases among Escherichia coli, Klebsiella pneumoniae, and Proteus mirabilis isolates at a veterans medical center. J Clin Microbiol 2000;38:1791-6.

9. Fortineau N., Poirel L., Nordmann P. Plasmid-mediated and inducible cephalosporinase DHA-2 from Klebsiella pneumoniae. J Antimicrob Chemother 2001;47:207-101.
10. Moland E.S., Black J., Ourada A., et al. Occurrence of newer betalactamases in Klebsiella pneumoniae isolates from 24 U.S. hospitals. Antimicrob Agents Chemother 2002;46:3837-42.

11. National Committee for Clinical Laboratory Standards. Performance standards for antimicrobial susceptibility testing. Twelfth informational supplement. Approved standard M100S12. 2002; NCCLS, Wayne, Pa.

12. Black J.A., Thomson K.S., Pitout J.D. Use of beta-lactamase inhibitors in disk tests to detect plasmid-mediated AmpC betalactamases. J Clin Microbiol 2004;42:2203-6.

13. Perez-Perez F.J., Hanson N.D. Detection of plasmid-mediated AmpC beta-lactamase genes in clinical isolates by using multiplex PCR. J Clin Microbiol 2002;40:2153-62.

14. Lee Y., Lee C.S., Kim Y.J., et al. Development of DNA chip for the simultaneous detection of various beta-lactam antibioticresistant genes. Mol. Cells 2002;14:192-7.

15. Sanders C.C. Chromosomal cephalosporinases responsible for multiple resistance to newer beta-lactam antibiotics. Annu Rev Microbiol 1987;41:573-93.

16. Zhang Y.L., Li J.T., Zhao M.W. Detection of ampC in Enterobacter cloacae in China. Int J Antimicrob Agents 2001;18:365-71.

17. Kirschner P., Meier A. Böttger E.C. Genotypic identification and detection of mycobacteria - facing novel and uncultured pathogens. In: D.H. Persing, T.F. Smith, F.C., Tenover, T.J. White (Eds.), Diagnostic molecular microbiology principles and applications. American Society for Microbiology, Washinton, D.C. 1993.

18. Coudron P.E., Hanson N.D., Climo M.W. Occurrence of extendedspectrum and AmpC beta-lactamases in bloodstream isolates of Klebsiella pneumoniae: isolates harbor plasmid-mediated FOX5 and ACT-1 AmpC beta-lactamases. J Clin Microbiol 2003; 41:772-7.

19. Bret L., Chanal-Claris C., Sirot D., et al. Chromosomally encoded AmpC-type b-lactamase in a clinical isolate of Proteus mirabilis. Antimicrob Agents Chemother 1998;42:1110-14.

20. Coudron P. E., Moland E. S., Sanders C. C. Occurrence and detection of extended-spectrum beta-lactamases in members of the family Enterobacteriaceae at a veterans medical center: seek and you may find. J Clin Microbiol 1997;35:2593-7.

21. Sutcliff J.G. Nucleotide sequence of the ampicillin resistance gene of Escherichia coli plasmid pBR322. Proc Natl Acad Sci USA. 1978; 75:3737-41.

22. Rottman M., Benzerara Y., Hanau-Bercot B., et al. Chromosomal ampC genes in Enterobacter species other than Enterobacter cloacae, and ancestral association of the ACT-1 plasmid-encoded cephalosporinase to Enterobacter asburiae. FEMS Microbiol Lett 2002;210:87-92.

23. Lee S.H., Kim J.Y., Shin S.H., et al. Dissemination of SHV-12 and characterization of new AmpC-type beta-lactamase genes among clinical isolates of Enterobacter species in Korea. J Clin Microbiol 2003;41:2477-82.

24. Poirel L., Guibert M., Girlich D., et al.. Cloning, sequence analyses, expression, and distribution of $a m p C-a m p R$ from Morganella morganii clinical isolates. Antimicrob Agents Chemother 1999;43:769-76.

25. Verdet C., Arlet G., Barnaud G., et. al. A Novel Integron in Salmonella enterica Serovar Enteritidis, Carrying the $b l a_{\mathrm{DHA}-1}$ Gene and Its Regulator Gene ampR, Originated from Morganella morganii. Antimicrob Agents Chemother 2000;44:222-5.

26. Livermore D.M., Brown D.F. Detection of beta-lactamasemediated resistance. J Antimicrob Chemother 2001;48:(Suppl1)59-64.

27. Chow J.W., Fine M.J., Shlaes D.M., et. al. Enterobacter bacteremia: clinical features and emergence of antibiotic resistance during therapy. Ann Intern Med 1991;115:585-90.

28. Kaye S. K., Cosgrove S., Harris A., et. al.. Risk factors for emergence of resistance to broad-spectrum cephalosporins among Enterobacter spp. Antimicrob Agents Chemother 2001;45:2628-30. 